\title{
Biodiesel Production from Waste Vegetable Oil (Sunflower) Obtained from Fried Chicken and Plantain
}

\section{Benard A Udeh*}

Faculty of Environmental Engineering, Department of Environmental Sciences, Cyprus International University, Haspolat, Nicosia, Turkey

\begin{abstract}
Waste sunflower oil sourced from fried chicken and plantain was used for biodiesel production in this study. During the transesterification process, $161 \mathrm{ml}$ of ethanol containing $96 \%(\mathrm{v} / \mathrm{v})$ was added to $250 \mathrm{ml}$ of waste sunflower oil using $\mathrm{NaOH}$ as the catalyst at different concentrations $(2.0 \%$ to $4.0 \%)$ and temperatures $\left(45^{\circ} \mathrm{C}, 60^{\circ} \mathrm{C}\right.$, $70^{\circ} \mathrm{C}$ and $85^{\circ} \mathrm{C}$ ). Biodiesel yield of $88.6 \%$ was obtained at the temperature of $70^{\circ} \mathrm{C}$ in $3.0 \% \mathrm{NaOH}$. Viscosity test at room temperature and specific gravity evaluation recorded $2.81 \mathrm{~cm}^{2} \mathrm{~s}^{-1}$ and $0.912 \mathrm{Kg} / \mathrm{m}^{3}$ respectively. The high energy density obtained from waste sunflower biodiesel blend is comparable with the hydrocarbon-based fossil fuel, an indication for smooth engine runs. This means that waste sunflower oil could be a veritable material for energy production as the alternative to greenhouse issues of fossil fuel diesel blend.
\end{abstract}

Keywords: Biodiesel; Trans-esterification; Waste; Sunflower oil; Energy

\section{Introduction}

Trans-esterification and esterification are chemical processes used in the production of biodiesel/or biofuel from animal fats/oil [1]. Biodiesels can be produced from vegetable oil, animal fats and cooking oil, it is biodegradable, non-toxic and has few emissions when compared to fossil fuel based product. As fossil fuels are depleting year after year, the emergence of new technologies should be paramount in order to produce fuel from waste and renewable biomass [2].

In early 1970's acute fuel shortage culminated diversifying fuel resources and thus biodiesel as fatty esters were developed as alternatives to petroleum diesel. Afterwards towards 1990's there was a kind of relieve from atmospheric pollution from fossil fuel-based diesel and interest started rising on the use of trans-esterification and esterification alternative. Nowadays, diesel engines require cleaner burning, the stable fuel that will operate under a variety of conditions [3]. However, the resurgence of biodiesel from waste and animal fats has been affected by regulations and legislations in different countries in order to minimize pollution and to rule out the competition with food industries. Many of the regulations and laws are centered on promoting the countries agro-economy, national security and reducing climate change.

Trans-esterification is a technique used in the soap industries for soap and detergent production in many industries. Biodiesel is produced in a similar chemical process as soap using basecatalyzed trans-esterification as it is the most economical process, requiring very low temperatures and pressures while producing $98 \%$ conversion yield [4].

During trans-esterification process, the fatty acid/glyceride is reacted with alcohol in the presence of a catalyst, usually a very strong alkaline such as potassium hydroxide or sodium hydroxide $[5,6]$. Alcohol reacts with the fatty material in the presence of a catalyst to form biodiesel or mono-alkyl ester and glycerol. A successful transesterification reaction is characterized by separation of methyl ester (biodiesel) and glycerol layers after the reaction [7]. Heavier coproduct, glycerides settles at the bottom, while the lighter one biodiesel occupies top. The solid part, glyceride may be collected and sold for other industrial uses, in cosmetics, detergents or pharmaceuticals.
Crude glyceride phase which is left after trans-esterification may require purification prior to use [7].

In this study, ethanol was used and catalyzed with sodium hydroxide to form biodiesel and crude glyceride that is soapy in nature aimed to produce biodiesel fossil fuel alternative blend that is carbon neutral with smoke-free engines. The product yield according to literature is less than 10 percent (10\%) carbon dioxide only, with no other gasses emissions that could be seen in fossil fuel-based diesel blend [8]. Low amount of carbon dioxide released could be used by green plants for process metabolism during photosynthesis. These will reduce to barest minimum greenhouse issues/other gaseous contaminants of longaccumulated flora and fauna fossil fuel biodiesel made products in industrial uses, in cosmetics, detergents or pharmaceuticals and perhaps will minimize the current issue of climate change that is ravaging global economy at the moment. Crude glyceride phase which is left after transesterification may require purification prior to use [7].

\section{Material and Methods}

\section{Raw materials and chemicals}

5 liters of waste vegetable oil was collected from a restaurant in Cyprus international university and kept at a room temperature for one day to enable settling. Thereafter, 1 liter was collected and filtered to remove impurities, then heated to rule out the presence of water and kept for further investigation. Ethanol $96 \%(\mathrm{v} / \mathrm{v})$ and between $(2.0 \%$ to $4.0 \%$ ) sodium hydroxide that were laboratory stored was used in this study as the catalyst.

\section{Purification}

One liter of the waste sunflower oil sample was allowed to pass

"Corresponding author: Benard A Udeh, Faculty of Environmental Engineering Department of Environmental Sciences, Cyprus International University, Haspolat Nicosia, Turkey, Tel: +905428788169; E-mail: becbenarcsudeh@gmail.com

Received March 08, 2017; Accepted March 30, 2017; Published Apriil 17, 2017

Citation: Udeh BA (2017) Biodiesel Production from Waste Vegetable Oil (Sunflower) Obtained from Fried Chicken and Plantain. J Pet Environ Biotechnol 7 321. doi: 10.4172/2157-7463.1000321

Copyright: (c) 2017 Udeh BA. This is an open-access article distributed under the terms of the Creative Commons Attribution License, which permits unrestricted use, distribution, and reproduction in any medium, provided the original author and source are credited. 


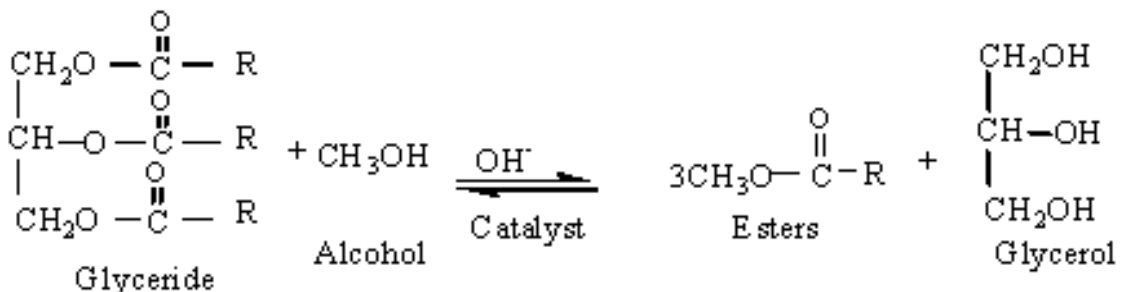

Source: www.esru.strath.ac.uk/EandE/Web_sites/02-03/biofuels/what_biodiesel.htm

Figure 1: Process application of ethyl ester biodiesel.

\begin{tabular}{|c|c|c|c|c|c|}
\hline Time (Minutes) & Temp $\left({ }^{\circ} \mathrm{C}\right)$ & $\mathrm{NaOH} \%(w / v)$ & Oil (w/w) & Ethanol (v/v) & Biodiesel yield (\%) \\
\hline 120 & 45 & 2 & 250 & 161 & 35.2 \\
\hline 180 & 60 & 2.5 & 250 & 161 & 52.1 \\
\hline 240 & 70 & 3 & 250 & 161 & 88.6 \\
\hline 300 & 80 & 3.5 & 250 & 161 & 87.8 \\
\hline 340 & 85 & 4 & 250 & 161 & 62 \\
\hline
\end{tabular}

Table 1: Evaluation of biodiesel yield (\%) during ethanol, waste sunflower oil trans-esterification at different temperatures, time and catalyst (NaOH) concentration.

through a sedimentation tank for purification. Then filtered, residue weighed and kept for further investigation. About 1 liter of the sample was weighed and then heated to a temperature of $105^{\circ} \mathrm{C}$ for $2 \mathrm{~h}$ in order to remove any impending water. After which the content was reweighed to record the difference in volume, then kept at a room temperature for viscosity test and specific gravity evaluation.

\section{Sodium hydroxide catalyzed trans-esterification}

$250 \mathrm{ml}$ of waste vegetable oil was transferred to $500 \mathrm{ml}$ beaker and heated to different temperatures of $45^{\circ} \mathrm{C}, 60^{\circ} \mathrm{C}, 70^{\circ} \mathrm{C}$ and $80^{\circ} \mathrm{C}$ in a water bath. A solution containing $(2.0 \%$ to $4.0 \%(\mathrm{w} / \mathrm{v})$ of sodium hydroxide and $161 \mathrm{ml}$ of $96 \%$ ethanol were added individually and vigorously stirred using a magnetic stirrer, and reactions were allowed for 120340 minutes. Except for temperature, time and catalyst concentration variation, all order conditions such as the concentration of ethanol, and the waste sunflower oil volume remained constant. After which the samples were removed and poured into separating funnel and kept overnight to settle, then the biodiesel in the upper layers was decanted from the glyceride and kept for next step.

\section{Washing and drying}

The impure biodiesel obtained were treated with water and acetic acid to remove soap contaminants (ethanol, $\mathrm{NaOH}$, glycerol), then passed through a washing tank for agitation/air bubbled for 60 minutes. Thereafter, the contents were allowed to settle in the settling tank and the wastewater removed and discarded. Since untreated biodiesel contains impurities such as soap, ethanol, fatty acids, sodium hydroxide, glycerides, washing, and drying was done to remove these contaminants which may affect the engine cranks and cause engine knock [9]. Washing was achieved using acetic acid and water that followed repeated agitation to remove grease and other soapy substances from the system.

\section{pH and specific gravity}

Washing of impure biodiesel continued until pH near neutrality (7.25) was achieved. And specific gravity was determined using a hydrometer. The amount of biodiesel produced after the trans-esterification processes were calculate using the equation (1) [10] (Figure 1).

Effect of temperature/time/catalyst concentration on biodiesel yield

Three different conditions (Temperature, time and catalyst concentration) were used to evaluate the optimal conditions for biodiesel yield. Temperature estimation was used to evaluate the optimal temperature condition required for waste vegetable oil conversion to biodiesel yield (Table 1). Calculation of Specific gravity and viscosity evaluation were calculated by Oguntal method [10] as shown in equation (2):

$$
\text { Yield }=\frac{\text { Amount of biodiesel produced }}{\text { Amount of Sunflower oil used }} \times 100
$$

Specific gravity determined is given by Oguntola et al.

Specific gravity $=\frac{\mathrm{W}_{3}-\mathrm{W}}{\mathrm{W}_{4}-\mathrm{W}}$

Where $\mathrm{W}=$ weight of specific gravity bottle

$\mathrm{W}_{3}=$ weight of specific gravity bottle + sample

$\mathrm{W}_{4}=$ weight of specific gravity bottle + water

\section{Results and Discussion}

Purification of sample materials prior to transesterification is a very important indicator for the production of grade 'A' biofuel in the biodiesel producing industry. This is essential in order to overcome the issues of environmental pollution and climate change that culminate contaminated fossil diesel and petroleum hydrocarbon fuels.

During purification, the total number of residues that occupy sample volume in one liter of waste sunflower oil used was $2.4 \mathrm{~g}(\mathrm{w} / \mathrm{w})$ Thus the quantity of the residue so obtained was large enough to affect the quality of the biodiesel which may invariably cause cracking and engine damage.

In this study, several conditions which included the molecular ratio of the ethanol, heating temperature, Concentration of sodium hydroxide, and time interval were considered as pre-requisite for alkaline catalyzed esterification process. The molar ratio of 10:1 ethanol to waste sunflower oil with $\mathrm{NaOH}(3 \%$ w/v) catalyzed reaction yielded a high amount of biodiesel giving rise to 2:1 glycerol volume to biodiesel produced. The amount of biodiesel produced increased with the increase in temperature at a constant ethanol amount and waste sunflower oil volume (Table 1). Alkaline transesterification in the molar ratio of 10:1 ethanol to oil at the temperature of $70^{\circ} \mathrm{C}$ yielded a high amount of biodiesel. The volume of biodiesel obtained increased with 


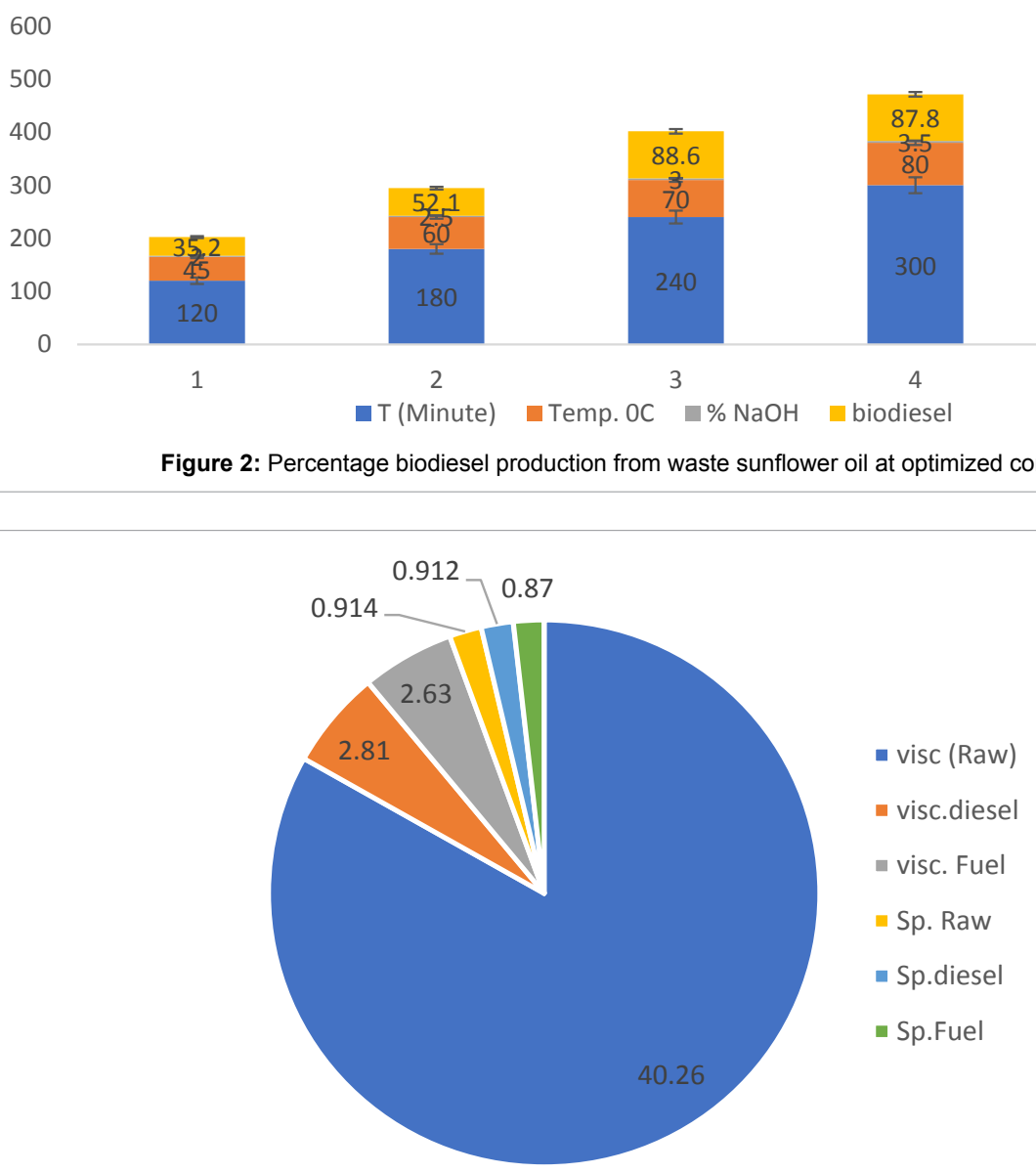

Figure 3: Summarizing viscosity (Visc.) and the specific gravity (sp.) of the raw sunflower oil, biodiesel waste sunflower blend and fuel diesel at room temperature.

\begin{tabular}{|c|c|c|c|}
\hline Viscosity $\left(\mathbf{c m}^{2 \mathrm{~s}-1}\right)$ & $\begin{array}{c}\text { Waste sunflower } \\
\text { oil }\end{array}$ & $\begin{array}{c}\text { Biodiesel from waste } \\
\text { sunflower oil }\end{array}$ & Fuel diesel \\
\hline At room temp. & 40.26 & 2.81 & 2.634 \\
\hline $\begin{array}{c}\text { Specific gravity at } \\
\text { room temp. }\left(\mathrm{Kg} / \mathrm{m}^{3}\right)\end{array}$ & 0.914 & 0.912 & 0.87 \\
\hline
\end{tabular}

Table 2: Comparison of Specific gravity and viscosity of raw waste sunflower oil, produced biodiesel and fuel diesel.

increase in temperature at a constant volume of ethanol with different catalyst concentration until an ambient temperature of $70^{\circ} \mathrm{C}$ was exceed. Temperature effect on the rate of biodiesel yield was reported by Abba et al. on neem seed biodiesel conversion which increased with increase in temperature. In this study waste, vegetable oil conversion increased with the increase in temperature. At room temperature, the chemical kinetics of the oil requires a higher temperature to increase the fractionation of the waste oil molecules and that is why the increase in temperature greatly influenced the corresponding volume of biodiesel production.

Table 1 clearly shows that temperature can impact biodiesel production [11]. At the temperature of $45^{\circ} \mathrm{C}$ yield was very low which corresponds to the theory of chemical reaction kinetics, that increase in temperature will lead to the corresponding increase in molecular fractions that characterizes high kinetic rate [10]. At the temperature of $45^{\circ} \mathrm{C}$ biodiesel yield from waste vegetable oil was very low, the yield increased with increase in temperature. At the temperature of $45^{\circ} \mathrm{C}$, $35.2 \%$ waste vegetable oil biodiesel was harvested which increased to
$52.2 \%$ at the temperature of $60^{\circ} \mathrm{C}$, the yield continued to increase until after $70^{\circ} \mathrm{C}$ with a maximum yield of $88.6 \%$. The increase in yield with the increase in temperature could be as the result of the acceleration of the saponification reaction of triglycerides [10]. It was observed that at a higher temperature of $80^{\circ} \mathrm{C}$ the yield started reducing this could be attributed to the loss of ethanol to evaporation at above $70^{\circ} \mathrm{C}$ which may have occurred due to temperature effect on conversion rate during transesterification when the optimum temperature for ethanol was exceeded [12]. This indicates that at ambient temperatures the amount of biodiesel yield is high compared to lower/or higher temperatures, the above phenomenon exhibited by waste sunflower oil transesterification process catalyzed by $\mathrm{NaOH}$ in this study reveals greater energy efficiency required for low carbon evolution. Olugbenga had a similar report with neem seed oil when treated beyond $65^{\circ} \mathrm{C}$ methanol escaped as the evaporation point was exceeded which resulted in decreasing the amount of biodiesel produced.

At different concentrations of $\mathrm{NaOH}$ and varying temperature conditions, biodiesel yield increased with catalyst concentration until after $3.0 \%(\mathrm{w} / \mathrm{v}) \mathrm{NaOH}$. Yield started decreasing at a concentration above $3.0 \% \mathrm{NaOH}$, this could be attributed to alkaline inhibition. Highest biodiesel yield was obtained with $3.0 \%$ (w/v) $\mathrm{NaOH}$ in 161 $\mathrm{ml}$ ethanol at the temperature of $70^{\circ} \mathrm{C}$. The yield of $88.6 \%$ biodiesel waste vegetable oil blend clearly influenced the rate of reaction during transesterification at the ambient temperature. The high amount of biodiesel yield was dependent on the temperature and increased with 
increase in temperature until after $70^{\circ} \mathrm{C}$ the yield started decreasing due to evaporation of ethanol after the boiling point was exceeded (Table 1 and Figure 2). Catalyst concentration evaluation on the amount of biodiesel production with waste sunflower oil and time estimation was used to determine the required time for optimal production. The result obtained from this study shows that percentage yield is dependent on the temperature with respect to time. The temperature of $70^{\circ} \mathrm{C}$ at 180 minutes yielded $88.6 \%$ biodiesel in $3.0 \% \mathrm{NaOH}(\mathrm{w} / \mathrm{v})$ concentration and the yield started decreasing at time interval beyond 180 minutes which shows that the accelerated reaction increased with the temperature. This phenomenon is better explained in Figure 3 in this study.

In the furtherance of this study as is shown in Table 2, the viscosity of waste sunflower oil $\left(40.26 \mathrm{~cm}^{2} \mathrm{~s}^{-1}\right)$ is near the conventional plant vegetable oil extract of $40 \mathrm{~cm}^{2} \mathrm{~s}^{-1}$ which corresponds to reports on the viscosity of pure vegetable oil by Oguntola et al. in the year 2010. At room temperature waste vegetable oil biodiesel viscosity $\left(2.81 \mathrm{~cm}^{2}\right.$ $\left.\mathrm{s}^{-1}\right)$ was higher than the fossil fuel type $\left(2.634 \mathrm{~cm}^{2} \mathrm{~s}^{-1}\right)$ which indicates high octane rating from waste sunflower oil biodiesel blend. This will enhance normal engine runs with minimized particulate matter (smokes) when compared to petroleum hydrocarbon made diesel fuel. Car engines that use high octane rating fuels from reports are more durable and have fewer pollutants than those that are operated with low-grade diesel fuel [13].

The result also indicates that waste sunflower oil made diesel is denser than the petroleum diesel and this will enhance high volatility for a high-speed run in diesel motor engines. Specific gravity is a very important parameter and is usually used in the determination of grade 'A' fuel. The specific gravity of sunflower waste vegetable oil diesel (0.914) against the fossil fuel-based diesel (0.87), indicates that waste vegetable oil diesel blend has higher energy impact when compared to petroleum hydrocarbon based diesel product. The calorific value of waste sunflower oil $(40.0 \mathrm{MJ} / \mathrm{Kg}$ is within the range from literature report of $(40-45 \mathrm{MJ} / \mathrm{Kg})$. These high energies dissipated by waste sunflower oil in this study will enhance the capacity of automobiles to cover several miles in a short period of time when compared to conventional fossil fuel blend. The viscosity of sunflower diesel blend was very close to the convectional hydrocarbon-based diesel product which discourages hardware modifications for waste sunflower diesel blend by Deng et al. (Table 2). Interestingly, waste sunflower oil made biodiesel according to this study has a high yield of biodiesel with high energy impact produced in terms of high density expected for clean engine runs and zero particulate matters (Table 2).

\section{Conclusion}

In this study, biodiesel was produced using waste sunflower vegetable oil. The higher density value of biodiesel produced by waste vegetable oil material indicates high energy efficiency of waste vegetable oil made diesel product compared to the conventional fossil fuel diesel product. The viscosity of waste vegetable oil diesel blend was higher than the petroleum oil type which refers to high octane value that is useful for normal combustion and cleaner engine with reduced air pollutants such as $\mathrm{CO}_{2}$, smoke and particulate matters from waste pipe. This will enhance lubrication of the injection engine with the elimination of any material that may affect engine component. From the temperature evaluation, high biodiesel yield was obtained at $70^{\circ} \mathrm{C}$ with reduced yield at $80^{\circ} \mathrm{C}$ which indicates ethanol efficiency in waste oil biodiesel yield at $70^{\circ} \mathrm{C}$. Since the process yielded $88.6 \%$ biodiesel using sunflower waste oil, advocating the application of waste sunflower oil for commercial production is imperative and should be encouraged for de-carbonization of global economy.

\section{References}

1. Anya UA, Nwobia NC, Ofoegbu O (2012) Optimized reduction of free fatty acid content on neem seed oil, for biodiesel production. J Basic App Chem 2: 21-28.

2. Fatehi $P$ (2013) Production of biofuels from cellulose of woody biomass

3. Ramadhas AS, Jayaraj S, Muraleedharan C (2005) Biodiesel production from high FFA rubber seed oil. Fuel 84: 335-340.

4. Aghan D (2005) Progress in energy and combustion. Elsevier 31: 406-487.

5. Patil P, Veera G, Mannarswamy A, Deng S, Cooke P, et al. (2011) Optimization of microwave-assisted transesterification of dry algal biomass using response surface methodology. Bio-resource Technology 102: 1399-1405.

6. Patil PD, Gude VG, Camacho LM, Deng S (2010) Microwave-assisted catalytic transesterification of Camelina sativa oil. Energy Fuels 24: 1298-1304.

7. Oguntola JA, Opeoluwa D, Adedoyin AS (2010) Production and testing of coconut oil biodiesel and its blend. Leonardo J Sci p: 95-104.

8. Aworanti OA, Agarry SE, Ajani AO (2013) Statistical optimization of process variables for biodieselproduction from waste cooking oil using heterogeneous base-catalyst. Br Biotechnol J 3: 116-132

9. Lang X, Dalai AK, Bakhshi NN, Reaney MJ, Hert PB (2001) Preparation and characterization of biodiesels from various bio-oils. Bio-resource Technology 80: $53-62$.

10. Abbah EC, Nwandikom GI, Egwuonwu CC, Nwakuba NR (2016) Effect of reaction temperature on the yield of biodiesel from neem seed oil. American Journal of Energy Science 3: 16-20.

11. Olugbenga OA, Layokun SK (2013) Optimization of two-step transesterification production of biodiesel fromNeem (Azadirachta indica) Oil. International Journal of Energy and Environmental Engineering (IJEEE) 4: 39.

12. Ragit S (2011) Optimization of neem methylester from transesterification process and fuel characterization as a diesel substitute. Biomass and Bioenergy 35: 1138-1144.

13. Sthyal T, Manivannan A (2013) Biodiesel production from oil using two-step trans-esterification. International Journal of Engineering Research and Application (IJERA) 3: 488-492. 